\title{
ANALISIS FRAMING PERNYATAAN RESMI PARA AKTOR DALAM KRISIS DI KOMPETISI SEPAKBOLA INDONESIA: KASUS POLEMIK JUARA BHAYANGKARA FC DI LIGA 1 TAHUN 2017
}

\author{
Narayana Mahendra Prastya \\ Program Studi Ilmu Komunikasi, Fakultas Psikologi dan Ilmu Sosial Budaya, Universitas Islam Indonesia \\ Jalan Kaliurang KM 14.5, Besi, Sleman, Daerah Istimewa Yogyakarta 55584 Email : narayana@uii.ac.id
}

\begin{abstract}
The objetives of this articles is to analyse how the actors that involved in the Indonesian football conflict frame their official statement. The conflict in this articles is the controversy of Bhayangkara FC in competition Liga 1 sesaon 2017. The controversy occurs when Indonesian Football Association's decision give advantage for Bhayangkara FC to win the league. This decision arouse complain from several Liga I's contestant. This articles using frame by Robert N.Entman as analysis tool. The research objets are official statements taken from the actors' official website. The limitation of the actors' are: Bali United and Madura United as the league contestant that think the PSSI's decision is unfair; PSSI as the Indonesian FA, and PT Liga Indonesia Baru (PT LIB) as the competition organizer. The results shows that all parties, except PT LIB, are blaming each other in this case. The official statement by the actors are influenced on their own interest
\end{abstract}

Keywords : crisis communication, frame analysis, internet public relations, sport communication, sport public relations

\section{PENDAHULUAN}

Industri olahraga merupakan bisnis yang rentan terhadap krisis. Perilaku negatif dari individu pesepakbola dan/ atau pelatih (seperti pelanggaran etika dan/ atau aturan, skandal kehidupan pribadi), persoalan finansial klub, cara pengelolaan organisasi olahraga, keru-suhan supporter, dan permasalahan dengan sponsor (Isaacson, 2010; Manoli, 2016; Syadzwina, 2016) adalah sebagian contoh peristiwa di dunia olahraga yang dapat memicu lahirnya krisis. Dengan kata lain, krisis di dunia olahraga adalah kejadian yang dapat memberikan pengaruh negatif terhadap citra individu atlet atau organisasi olahraga. Jika krisis tersebut menjadi semakin parah, maka dapat mengganggu kinerja atlet atau organisasi olahraga dalam mencapai tujuan, dan dapat mendatangkan kerugian finansial.

Tulisan ini menggunakan latar kasus polemik juara klub Bhayangkara FC di kompetisi Liga 1 Indonesia tahun 2017. Sejumlah peserta kompetisi Liga 12017 menilai keputusan Komisi Disiplin PSSI menguntungkan Bhayangkara FC untuk menjuarai kompetisi. Kondisi ini sempat menimbulkan konflik di antara pihak-pihak yang berkaitan dengan kompetisi.

Menurut Kriyantono (2012: 176) konflik merupakan ciri-ciri dari peristiwa krisis. Konflik terjadi akibat adanya perbedaan antara harapan dan kenyataan. Konflik memunculkan pro dan kontra di ranah publik akibat pemberitaan media massa dan atensi publik secara terus menerus 
Polemik itu muncul setelah Bhayangkara FC dinyatakan memenangi laga melawan Mitra Kutai Kartanegara (Mitra Kukar) dengan skor 3-0. Dalam pertandingan sesungguhnya, hasil akhir antara "The Guardian" (julukan Bhayangkara) melawan Naga Mekes (julukan Mitra Kukar) adalah imbang 1-1. Namun dalam perkembangan selanjutnya, Mitra Kukar dinyatakan kalah setelah Komisi Disiplin (Komdis) Persatuan Sepakbola Seluruh Indonesia (PSSI) menatuhkan hukuman pada Mitra Kukar karena menurunkan pemain yang tidak sah, Mohamed Sissoko. Seharusnya dalam pertandingan itu Sissoko tidak bisa bermain, karena masih menjalani hukuman larangan bermain.

Keputusan Komisi Disiplin PSSI didasarkan pada protes Bhayangkara FC kepada PT Liga Indonesia Baru (PT LIB) selaku operator kompetisi Liga 1 2017. Klub berjuluk "The Guardian" itu meniali seharusnya Mitra Kukar tidak bisa memainkan Sissoko, (dalam laga melawan Bhayangkara FC) karena pemain tersebut masih dalam masa hukuman larangan tampil. PT LIB kemudian meneruskan protes ini kepada PSSI.

Selanjutnya pada tanggal 28 Oktober 2017, Komdis PSSI mengeluarkan nota larangan bermain bahwa Sissoko terkena tidak boleh tampil di dua pertandingan selanjutnya (baca: https://www.pssi.org/ news/hasil-keputusan-komite-disiplin-pssi ).

Pihak Komisi Disiplin PSSI juga menge-luarkan sanksi baru bagi Mitra Kukar yakni denda Rp 100 juta dan dianggap kalah 0-3 dari Bhayangkara FC. Dengan kemenangan itu, maka Bhayangkara FC hanya butuh satu kemenangan lagi untuk menjadi juara Liga 12017.
Keputusan Komdis PSSI mendapatkan protes dari klub-klub yang saat itu masih memiliki peluang juara seperti Bali United dan Madura United. Pasalnya keputusan Komdis PSSI memperbesar peluang Evan Dimas dkk. untuk menjuarai Liga 12017. Keputusan ini juga dinilai ganjil, karena dalam aturan Liga 1 2017, pemain yang terkena kartu merah langsung akan terkena sanksi larangan bermain di satu pertandingan selanjutnya, bukan dua pertandingan selanjutnya (Pembelaan Mitra Kukar Soal Kasus Sissoko. URL: https://bola.kompas.com/ read/2017/11/08/19500308/pembelaanmitra-kukar-soal-kasus-sissoko)

Pada akhirnya Bhayangkara FC berhasil menyegel gelar juara Liga 12017 setelah menundukkan Madura United FC 3-1 melalui pertandingan yang diwarnai tiga kartu merah untuk pemain Madura United. Setelah pertandingan itu, kontroversi menyeruak ke ranah publik, di mana pihakpihak yang berkonflik saling melontarkan komentar mengecam satu sama lain.

Tulisan ini bertujuan untuk mengetahui bagaimana strategi komunikasi para aktor yang berkaitan dengan kasus polemik juara Bhayangkara FC ini. Utami (2014: 8-9) mendeskripsikan aktor sebagai individu, kelompok, atau organisasi yang saling berkaitan dalam sebuah konflik. Di antara para aktor, terjadi proses transaksi sosial yang bisa berupa kerjasama, persaingan, pertentangan, penggunaan kekerasan, konflik.

Konflik merupakan salah satu bentuk krisis di dunia olahraga. Menurut Novitaria (2017), potensi konflik dalam industry olahraga, baik itu internal mau pun antar organisasi, akan menarik perhatian media massa untuk meliputnya. Sedangkan menurut Bernstein (2012: 62), krisis yang menimpa 
dunia olahraga cenderung diberitakan secara negatif oleh pemberitaan media.

Namun begitu, aktivitas komunikasi krisis ini sendiri dipandang belum menjadi prioritas oleh pengelola klub olahraga. Ini ditunjukkan dengan pelaksanaan manajemen krisis yang tidak terstruktur dan sistematis. Hal tersebut tetap dilakukan, karena dapat memberikan hasil sesuai harapan sejauh ini.

Manajemen krisis, klub sepakbola cenderung tidak melalui tahap perencanaan, karena adanya perbedaan karakteristik krisis yang terjadi di seiap waktu. Perencanaan hanya dilakukan ketika krisis tersebut memiliki potensi dampak negatif yang besar. Alhasil, klub sepakbola hanya menunggu krisis itu mereda dengan sendirinya, menunggu krisis tersebut meredup karena digantikan oleh kejadian lain yang lebih menghebohkan. Sebenarnya ada satu hal lagi yang mereka jalankan, yakni melakukan langkah-langkah antisipasi sebelum rumor menyebar. Namun, langkah ini relatif jarang digunakan (Manoli, 2016)

Aktivitas komunikasi krisis dilakukan dengan mengandalkan kedekatan personal antara individu dari pihak divisi komunikasi klub dengan wartawan. Cara tersebut sejauh ini bisa efektif untuk meredam isu negatif agar tidak diberitakan ke media. Kelemahan dalam cara ini adalah klub sepakbola tersebut pada akhirnya bergantung dengan sosok individu yang menjadi penanggungjawab divisi komunikasi klub (Manoli, 2016).

Begitu pula dalam ranah akademis, belum banyak riset mengenai manajemen krisis di organisasi olahraga. Sulitnya akses untuk memperoleh data merupakan penyebab dari sedikitnya riset mengenai manajemen krisis di bidang olahraga. Ini disebabkan karena informasi tersebut merupakan hal yang bersifat sensitif, sehingga pihak informan cenderung enggan untuk menyampaikannya (Manoli, 2016)

Para aktor mempunyai cara pandang dan kepentingan yang berbeda dalam sebuah konflik. Perbedaan itu berpengaruh pada tindakan para aktor satu sama lain. Masingmasing aktor akan melakukan hal yang dapat mendatangkan manfaat paling besar bagi mereka. Peran yang dijalani para aktor adalah sebagai pihak yang berkonflik dan sebagai pihak yang memfasilitasi penyelesaian konflik.

Batasan aktor dalam tulisan ini adalah Madura United FC, Bali United FC (selaku klub peserta kompetisi Liga 1), PT Liga Indonesia Baru (selaku operator kompetisi) dan PSSI (selaku federasi sepakbola Indonesia). Ada pun objek penelitian adalah pernyataan resmi yang disampaikan oleh para aktor melalui media berbasis internet resmi (selanjutnya ditulis laman resmi) dari masing-masing.

Ada sejumlah manfaat mengenai penggunaan laman resmi organisasi. Pertama memungkinkan organisasi untuk memberikan informasi secara detil dan komplet sehingga dapat menangkal kemungkinan isu negatif (Dewa Broto, 2014), kedua menjangkau langsung kepada masyarakat dan media dengan cepat dan dalam jangkauan yang luas (Sabreyna \& Moertijoso, 2015) dan ketiga masyarakat dan pemangku kepentingan menjadikan laman resmi sebagai rujukan pertama untuk mencari informasi atau penjelasan berkaitan dengan isu negatif yang terjadi. Itu sebabnya organisasi harus selalu memperbarui informasi di laman resmi (Kitchin \& Purcell, 2017)

Pada umumnya organisasi memiliki dua jenis laman resmi yakni website resmi 
dan media sosial resmi. Perbedaan antara keduanya adalah sifat dari komunikasi, di mana website resmi berisfat satu arah dan media sosial memungkinkan organisasi untuk bisa berkomunikasi secara interaktif, dua arah, dengan publik. Dalam konteks olahraga adalah fans. Keduanya perlu digunakan dalam komunikasi krisis.

Di era internet, publik bukan lagi menjadi pihak penerima informasi yang pasif. Sebaliknya, mereka menjadi pencari informasi aktif, bahkan tidak jarang sangat agresif dalam arti sangat haus informasi, yang menginginkan memperoleh informasi dengan cepat (Brown, et.al., 2014: 177)

Website perlu dipergunakan untuk menyediakan informasi yang bersifat segera. Bahkan di beberapa organisasi olahraga, mereka memiliki dark-website atau darkwebpage, yakni website yang memuat khusus informasi-informasi terkini, penjelasanpenjelasan detil mengenai kasus krisis yang terjadi (Kitchin \& Purcell, 2017: 667-668)

Ada pun media sosial memiliki keunggulan memungkinkan komunikasi dua arah dengan publik. Dalam situasi krisis, publik (atau fans) akan berinteraksi dengan sesama fans, atlet, dan dengan wartawan olahraga, untuk memperoleh informasi. Dengan menggunakan media sosial, organisasi olahraga dapat memberikan respon secara langsung kepada fans (Brown, et.al., 2014: 182-184).

Namun segala kelebihan itu bisa berujung sia-sia ketika pihak organisasi tidak memanfaatkan dengan baik. Ini karena keberadaan internet di sisi lain membuat tugas tim manajemen krisis menjadi semakin sulit dibandingkan sebelumnya. Informasi baik dari sumber internal organisasi atau eksternal organisasi dapat menyebar dengan cepat melalui Facebook. Twitter, dan media sosial lainnya, semua memiliki potensi untuk mempengaruhi opini publik (Bernstein, 2012: 62). Bahkan, dalam dunia olahraga, akun anonim atau akun pseudonim pun dapat mempengaruhi opini publik (Siahaan, 2014: 177-180).

Dalamkonteks situasi dimana isu negatif beredar, maka kecepatan yang ditawarkan oleh internet semakin relevan bagi kebutuhan organisasi untuk segera menyebarkan informasi. Dengan segera menyampaikan informasi, maka organisasi dapat memastikan bahwa informasi dari organisasi bisa sampai lebih cepat kepada publik, dibandingkan dengan isu-isu liar. Pasalnya, ketika publik sudah meyakini sesuatu itu benar -sekalipun informasi yang ia terima tidak memiliki dasar, maka anggapan itu akan susah untuk diubah (Serba-nica \& Constantinescu, 2016). Dalam situasi krisis, persepsi dapat lebih kuat daripada fakta, persepsi dapat menjadi kebenaran (Kriyantono, 2012 : 246)

Cepat dan segera memang kata kunci untuk memaksimalkan manfaat internet. Namun ada kalanya cepat dimaknai sebagai tindakan terburu-buru. Alhasil, organisasi justru mempublikasikan kepada publik informasi yang salah.

Dalam kasus olahraga, sebagai contoh di tahun 2011, pengelola kompetisi sepakbola Liga Prima Indonesia (LPI) melalui website resminya menginformasikan bahwa kompetisi LPI berhenti di tengah jalan (tidak menyelesaikan satu musim penuh). Info tersebut telah banyak dikutip sebagai bahan berita oleh media massa. Namun tidak lama berselang juru bicara LPI menghubungi wartawan dan mengatakan bahwa ada ralat terhadap pengumuman tentang penghentian kompetisi, dan menyebut bahwa informasi di website menggunakan data yang keliru. 
Di waktu yang berdekatan dengan klarifikasi juru bicara LPI, informasi mengenai penghentian kompetisi telah hilang dari website resmi LPI (Prastya, 2011: 14-15).

Batasan dari pernyataan resmi adalah pernyataan dalam bentuk tertulis yang rinci. Itu sebabnya, pernyataan dari Bhayangkara FC tidak diteliti karena klub tersebut tidak mencantumkan pernyataan tertulis yang rinci, namun mencantumkan foto Mohamed Sissoko dengan caption "Mitra Kukar Akui Salah, Bhayangkara Juara". Pernyataan itu diunggah di akun resmi Instagram Bhayangkara FC (URL: https://www.instagram.com/p/ BbV7BoWns_N/?taken-by=bhayangkarafc. Tanggal akses: 11 Maret 2018). Penelusuran penulis ke website resmi Bhayangkara FC yang beralamat di bhayangkarafc.id juga tidak tercantum mengenai kasus tersebut (penelusuran terakhir tanggal 13 Mei 2018).

\section{PEMBAHASAN}

Penelitian ini menggunakan metode analisis framing terhadap pernyataan resmi yang disampaikan oleh Bhayangkara FC, Madura United, Bali United, PT Liga Indonesia Baru (PT LIB), dan PSSI. Pemilihan ini berdasarkan pengertian aktor , yakni organisasi yang saling terkait dalam sebuah permasalahan. Setiap aktor akan menjalani peran masing-masing, sesuai dengan kepentingan yang mereka usung (Utami, 2014). Bhayangkara FC, Madura United, dan Bali United adalah peserta kompetisi sepakbola Liga 1 2017. Kompetisi ini merupakan liga sepakbola resmi di bawah naungan PSSI selaku federasi sepakbola Indonesia. PSSI kemudian menyerahkan penyelenggaraan kompetisi kepada PT LIB sebagai operator kompetisi. Kewenangan PT LIB adalah menggelar pertandingan dan melaporkan hasilnya kepada PSSI. Dari laporan tersebut, apabila ditemukan adanya pelanggaran, maka PSSI kemudian akan menjatuhkan sanksi.

Dari masing-masing aktor, penulis mengambil satu sampel pernyataan resmi

Tabel 1. Pernyataan Resmi Masing-masing Aktor

\begin{tabular}{|l|l|l|l|}
\hline No & Nama Aktor & \multicolumn{1}{|c|}{ Judul Pernyataan } & \multicolumn{1}{c|}{ Sumber (URL) } \\
\hline 1 & Bali United & $\begin{array}{l}\text { Komdis PSSI Ubah Hasil Mitra Kukar } \\
\text { Kontra Bhayangkara FC, Ini Reaksi } \\
\text { Widodo dan Pemain Bali United }\end{array}$ & $\begin{array}{l}\text { http://www.baliutd.com/news/media-news/ } \\
\text { komdis-pssi-ubah-hasil-mitra-kukar-kontra- } \\
\text { bhayangkara-fc-ini-reaksi-widodo-dan-pemain- } \\
\text { bali-united/. Tanggal akses : 11 Maret 2018 }\end{array}$ \\
\hline 2 & Madura United & $\begin{array}{l}\text { Inilah Kompetisi 'Dagelan', } \\
\text { Dibumbui Ancaman, dan Madura } \\
\text { United pun Terancam Sanksi Lagi }\end{array}$ & $\begin{array}{l}\text { https://maduraunitedfc.com/2017/11/09/ } \\
\text { inilah-kompetisi-dagelan-dibumbui-ancaman- } \\
\text { dan-madura-united-pun-terancam-sanksi-lagi/. } \\
\text { Tanggal akses: 11 Maret 2018 }\end{array}$ \\
\hline 3 & PT LIB & $\begin{array}{l}\text { Spaso Borong Gol Kemenangan } \\
\text { Bhayangkara FC atas Madura } \\
\text { United }\end{array}$ & $\begin{array}{l}\text { https://liga-indonesia.id/berita/spaso-borong- } \\
\text { gol-kemenangan-bhayangkara-fc-atas-madura- } \\
\text { united. Tanggal akses: 11 Maret 2018 }\end{array}$ \\
\hline 4 & PSSI & $\begin{array}{l}\text { Krofesionalisme Harus Jaga Integritas dan } \\
\text { http://pssi.org/news/klub-harus-jaga-integritas- } \\
\text { dan-profesionalisme. Tanggal akses: 11 Maret } \\
2018\end{array}$ \\
\hline
\end{tabular}


mengenai posisi mereka dalam konflik ini. Pemilihan hanya pada aktor yang mempublikasikan pernyataan tertulis (Lihat Tabel 1).

Menurut Kriyantono (2014: 313, 315) framing merupakan cara organisasi untuk mempersuasi, mengontrol berbagai isu dan event dan memberikan makna. Melalui frame pesan, PR berusaha untuk mempengaruhi persepsi publik berkaitan dengan realitas, isu, kebijakan organisasi. Tujuannya agar publik memberikan penilaian yang positif terhadap tindakna yang diambil organisasi.

Penelitian ini menggunakan frame model Robert N.Entman. Framing model ini dapat membantu praktisi humas dalam menentukan frame yang paling efektif dan dapat memberikan manfaat bagi organisasi tersebut. Bagi humas organisasi, frame model ini dapat membantu untuk : (1) mendefinisikan persoalan atau menentukan apa yang jadi penyebab permasalahan baik itu yang mendatangkan keuntungan atau kerugian bagi organisasi; (2) mengidentifikasi siapa penyebab persoalan, baik itu dari internal atau eksternal organisasi; (3) memberikan penilaian moral tentang situasi yang menyebabkan masalah; dan (4) memberikan solusi dalam menyelesaikan persoalan (Zoch dan Molleda, 2006 : 282-283). Keempat komponen frame tersebut menjadi alat analisis pernyataan resmi para aktor.

\section{Bali United}

Bali United adalah pesaing terdekat Bhayangkara FC dalam perebutan gelar juara Liga 1 2017. Keputusan PSSI memberikan kemenangan pada "The Guardian" membuat poin "Serdadu Tridatu" - julukan Bali United- menjadi sama. Namun peluang juara Bali United menjadi mengecil, karena apabila point keduanya tetap sama hingga akhir musim, maka Bhayangkara FC tetap menjadi juara karena tim milik Kepolisian Republik Indonesia itu unggul dalam catatan head-to-head dengan Bali United.

Narasumber dalam pernyataan resmi dari Bali United adalah kepala pelatih (head coach) Widodo Cahyono Putro dan pemain (I Gede Sukadana dan Stefano Comvalius). Dalam mendefinisikan persoalan, Widodo mengungapkan adanya kejanggalan dalam keputusan Komisi Disiplin PSSI berkaitan dengan status larangan bermain Mohamed Sissoko. Dua hal janggal yang tertulis dalam pernyataan resmi itu adalah Nota Larangan Bermain (NLB) yang tidak sampai ke Mitra Kukar selaku klub pemilik Sissoko, dan NLB yang baru terbit di 2 November 2017, padahal di tanggal surat tertulis 28 Oktober 2017. Artinya, ada jeda waktu selama hampir satu pekan antara tanggal tertulis di NLB hingga penerbitan NLB.

Bali United menempatkan PSSI seba-gai pihak penyebab persoalan ini. Hal tersebut terungkap dalam judul pernyataan yakni "PSSI Ubah Hasil Pertandingan, ....". namun begitu, dalam teks pernyataan resmi, tidak ada yang menyebut PSSI.

Dalam hal membuat keputusan moral, tim yang bermarkas di Stadion Kapten Wayan Dipta ini mencantumkan pernyatan yang bersumber dari unggahan dua pemainnya yakni I Gede Sukadana dan Sylviano Comvalius. Sukadana menyebut keputusan Komisi Disiplin PSSI yang "memenangkan Bhayangkara FC" membuat kompetisi menjadi 
tidak seru lagi. Sementara Comvalius menyebut bahwa kompetisi Liga 1 selayaknya pertunjukan sirkus. Tidak ada penjelasan lanjut dari Comvalius mengenai kata-kata sirkus, tetapi pada umumnya dalam sirkus kita bisa melihat hal-hal yang tidak biasa, tidak diduga (seperti pertunjukan aksi binatang, aksi sulap) atau hal yang lucu (pertunjukan badut).

\section{Madura United}

Madura United menjadi lawan bagi Bhayangkara FC di pertandingan selepas keptusuan Komdis PSSI. Itu berarti, Fachrudin Aryanto dkk. berkesempatan untuk mengganjal pesaing langsung mereka di laga ini. Status pertandingan yang digelar di Gelora Bangkalan Madura ini adalah tanpa penonton, karena Madura United tengah terkena sanksi dari Komdis PSSI. Narsumber dalam pernyataan Madura United adalah manajer tim, Haruna Sumitro dan "seorang pemain yang tidak mau disebutkan namanya".

Dalam mendefinisikan persoalan, Madura United menyoroti pada situasi dalam penyelenggaraan pertandingan, di mana suporter Bhayangkara FC justru hadir di stadion. Padahal status pertandingan itu adalah tanpa penonton. Pihak Madura United mengeluhkan karena tindakan supporter tim tamu itu berisiko membuat "Sape Kerrab" julukan Madura United- mendapatkan sanksi tambahan. Dalam teks juga disebutkan secara detil apa yang dilakukan oleh suporter Bhayangkara FC di tribun VVIP dengan menuliskan "menata sendiri tribun VVIP dan menyiapkan snack".
Madura United memposisikan aparat keamanan, dalam hal ini pihak kepolisian, sebagai penyebab dari persoalan ini. Anggota polisi baik itu yang bertugas untuk menjaga pertan-dingan, atau pun polisi yang hadir di tribun Gelora Bangkalan guna mendu-kung Evan Dimas dkk. Untuk anggota polisi yang bertugas, Madura United menilai pengamanan terlalu berlebihan. Bahkan mendekati ruang ganti pemain Madura United, aparat keamanan ber-jumlah sangat banyak dan hal tersebut membuat pemain menjadi tertekan secara psikologis. Hal itu disebut sebagai "kejadian yang tidak terjadi di pertandingan sebelumnya". Dalam teks juga tertulis "tidak ada pengamanan di lorong tim Bhayangkara FC". Selain itu pihak tuan rumah juga mengungkapkan adanya ketidakjelasan dalam pengurusan izin pertandingan. Panitia pelaksana pertandingan mengklaim telah memperoleh izin pertandingan dari kepolisian, kemudian menjelang hari $\mathrm{H}$ ada kemungkinan izin tersebut akan ditarik kembali. Dalam teks juga tertulis adanya "ancaman untuk mencabut izin pertandingan".

Berkaitan dengan membuat keputusan moral, Madura United memberikan selamat kepada Bhayangkara FC namun dengan nada satir. Dalam teks tertulis bahwa Bhayangkara FC telah menjuarai "kompetisi guyonan". Dari pernyataan ini, pihak "Sape Kerrab" bermaksud menunjukkan bahwa mereka mampu bersikap sportif dengan memberikan selamat kepada lawan, sekaligus bermaksud menyindir bahwa Bhayangkara FC menjuarai kompetisi yang "tidak berkualitas" karena "tidak digarap dengan serius". Artinya, tidak 
perlu ada hal yang harus dibanggakan berlebihan.

\section{PT Liga Indonesia Baru (PT LIB)}

PT LIB merupakan operator kompetisi. Dalam menghadapi kasus ini, PT LIB bersikap sangat datar. Ini karena memang kewenangan PT LIB memang hanya menggelar kompetisi. Mengenai perkara sanksi kepada peserta kompetisi dengan segala konsekuensinya (termasuk pemberian kemenangan, pengurangan poin, dan lain-lain) merupakan domain dari PSSI.

Selepas pertandingan antara Madura United melawan Bhayangkara FC, PT LIB dalam website resminya lebih memilih fokus untuk memberitakan jalannya pertandingan tersebut. Dalam mendefinisikan persoalan, PT LIB menyoroti mengenai penampilan gemilang Ilija Spasojevic yang menyumbang dua gol dalam kemenangan 3-1 "The Guardian" atas "Sape Kerrab". Sebagai penyebab dari kemenangan itu adalah adanya tiga pemain Madura United yang menerima kartu merah dari wasit akibat melakukan pelanggaran.

Berkaitan dengan kemungkinan Bhayangkara FC juara, PT LIB hanya menyinggung dalam satu alenia (kurang lebih tiga baris) dengan menyebut "Bhayangkara FC bisa menjadi juara Liga 12017 (seusai laga melawan Madura United) seandainya PSSI menolak banding yang diajukan Mitra Kukar terkait hukuman saat laga melawan Bhayangkara FC"

Adapun untuk solusi untuk menyelesaikan masalah adalah Bhayangkara United tinggal menjaga performa hingga pertan-dingan terakhir (melawan PErsija Jakarta) untuk menyegel gelar juara (jika banding Mitra Kukar dikabulkan PSSI pen.)

\section{PSSI}

PSSI memiliki kewenangan dalam kompetisi sepakbola nasional mulai dari menjatuhkan sanksi, merevisi sanksi (jika pihak yang terkena hukuman mengajukan banding), bahkan hingga menghentikan kompetisi.

Dalam pernyataan berkaitan dengan kasus polemik juara Bhayangkara FC, narasumber dari PSSI adalah Ratu Tisha Destria selaku Sekretaris Jenderal PSSI.

PSSI mengatakan bahwa prosedur yang ditempuh PSSI dalam menjatuhkan sanksi kepada Sissoko sudah melalui prosedur yang benar. Konteks prosedur yang benar ini adalah telah melalui pertimbangan dengan berdasarkan aturan kompetisi (regulasi Liga 1) dan telah melalui prosedur yang tepat. Dalam teks tertulis mengenai mengenai pasal regulasi yang digunakan dan PSSI telah mengirimkan salinan sanksi kepada pihak Mitra Kukar pada tanggal 31 Oktober 2017, atau sebelum pertandingan melawan Bhayangkara FC.

PSSI secara tidak langsung menuding Mitra Kukar yang tidak teliti sebagai penyebab dari persoalan ini. Dalam teks sendirii PSSI menyatakan meminta semua klub profesinal harus bertindak profesional.

PSSI menyatakan dalam teks bahwa mereka berupaya untuk "..melindungi aspek integrity, profesionalisme klub dan quality of the game" sebagai dasar 
dari tindakan mereka. Intinya, PSSI ingin menyampaikan pada publik bahwa tindakan PSSI selama ini merupakan upaya untuk menjalankan tanggungjawab mereka dalam mewujudkan sepakbola yang berkualitas.

PSSI meminta kerjasama dari klub profesional peserta kompetisi untuk mengetahui tanggung jawab masingmasing, di mana dalam teks secara khusus menyoroti tentang pemain atau ofisial tim yang terkena hukuman larangan tampil. PSSI menegaskan bahwa klub harus memperhatikan hal tersebut, sehingga pemain dan ofisial yang didaftarkan saat pertandingan, adalah orang yang tidak sedang terkena sanksi.

Keempat organisasi, yakni Bali United, Madura United, PT LIB, dan PSSI mempublikasikan pernyataan di laman resmi masingmasing berkaitan dengan peristiwa ini menjelang dan segera setelah pertandingan antara Madura United versus Bhayangkara FC yakni antara tanggal 8-9 November 2017.

Penggunaan laman resmi dapat mem-percepat upaya organisasi untuk menyampaikan informasi yang detil dan komplet kepada masyarakat dan media dalam jangkauan yang luas. Selain itu, dalam situasi beredarnya isu negatif publik akan menjadikan laman resmi organisasi sebagai rujukan pertama dalam mencari informasi (Dewa Broto, 2014; Kitchin \& Purcell, 2017; Sabreyna \& Moertijoso, 2015).

Maksud dari informasi yang "detil dan komplet" tentu saja adalah informasi yang mendukung kepentingan organisasi. Menurut Utami (2014), dalam situasi konflik para aktor yang terlibat akan bertindak dan berkomunikasi sesuai dengan kepentingan mereka. Melalui pernyataan resmi, organisasi berusaha untuk mempengaruhi opini publik secara positif karena dalam situasi krisis, organisasi perlu memperhatikan bagaimana persepsi masyarakat mengenai organisasi terse-but. Yang perlu diperhatikan adalah, dalam situasi krisis persepsi dapat diyakini sebagai fakta. Ketika publik sudah memiliki angapan tersendiri mengenai organisasi, maka anggapan itu akan sulit untuk diubah (Kriyantono, 2012; Kriyantono 2014; Serbanica \& Constantinescu, 2016).

Terlebih lagi, di era internet seperti saat ini, siapa pun dapat menyebarkan informasi. Organisasi harus sesegera mungkin memberikan penjelasan, agar tidak keduluan sumber informasi lain. Bahkan dalam konteks olahraga, akun-akun anonim atau pseudonim pun juga dapat mempengaruhi opini publik (Bernstein, 2012; Siahaan, 2014)

Kedua klub yang merasa dirugikan, Bali United dan Madura United, menggunakan strategi penolakan (denial) dengan secara khusus menuding pihak lain sebagai penyebab krisis (scapegoating). Sementara PSSI menggunakan strategi justifikasi yang menyatakan bahwa tindakan mereka sudah benar (mengenai strategi baca Brown, et.al. 2014) Berkaitan dengan perbandingan bingkai frame pernyataan resmi, lihat Tabel 2.

\section{PENUTUP}

Di bagian ini penulis akan memaparkan sejumlah kesimpulan serta saran bagi penelitian selanjutnya. Kesimpulan penelitian adalah dalam situasi krisis atau saat menghadapi isu negatif, organisasi olahraga di Indonesia menggunakan laman resmi sebagai media untuk menyampaikan informasi. Melalui laman resmi ini, masing- 
Tabel 2.

Perbandingan Frame Pernyataan Resmi Antar Aktor

\begin{tabular}{|c|c|c|c|c|}
\hline $\begin{array}{l}\text { Aktor } \\
\text { Komponen } \\
\text { framing }\end{array}$ & Bali United & Madura United & PT LIB & PSSI \\
\hline $\begin{array}{l}\text { Pendefinisian } \\
\text { masalah }\end{array}$ & $\begin{array}{l}\text { Surat keputusan } \\
\text { sanksi PSSI tidak } \\
\text { sampai ke klub } \\
\text { bersangkutan } \\
\text { (Mitra Kukar) }\end{array}$ & $\begin{array}{l}\text { Kehadiran supporter tim } \\
\text { Bhayangkara FC dalam laga } \\
\text { berstatus tanpa penonton } \\
\text { Kehadiran polisi dirasa berlebihan } \\
\text { sehingga menurunkan mental } \\
\text { bertanding pemain Madura } \\
\text { Ancaman dari polisi untuk } \\
\text { mencabut izin pertandignan yang } \\
\text { sebelumnya telah diperoleh }\end{array}$ & $\begin{array}{l}\text { Status juara } \\
\text { Bhayangkara } \\
\text { FC masih } \\
\text { menggantung }\end{array}$ & $\begin{array}{l}\text { Keputusan Komdis } \\
\text { PSSI sudah } \\
\text { berdasrkan dasar } \\
\text { hukum yang } \\
\text { kuat dan melalui } \\
\text { prosedur yang } \\
\text { berlaku sehingga } \\
\text { tidak perlu } \\
\text { dipertanyakan }\end{array}$ \\
\hline $\begin{array}{l}\text { Penyebab } \\
\text { masalah }\end{array}$ & PSSI & Kepolisian & $\begin{array}{l}\text { Masih } \\
\text { menunggu hasil } \\
\text { dari banding } \\
\text { Mitra Kukar }\end{array}$ & $\begin{array}{l}\text { Mitra Kukar yang } \\
\text { tidak teliti }\end{array}$ \\
\hline $\begin{array}{l}\text { Membuat } \\
\text { penilaian moral }\end{array}$ & $\begin{array}{l}\text { Keputusan Komisi } \\
\text { Disiplin PSSI } \\
\text { janggal, membuat } \\
\text { kualitas kompetisi } \\
\text { Liga } 1 \text { menjadi } \\
\text { turun, Liga } 1 \text { tak } \\
\text { ubahnya seperti } \\
\text { sirkus }\end{array}$ & $\begin{array}{l}\text { Bersikap sportif dengan } \\
\text { memberikan selamat pada } \\
\text { Bhayangkara FC } \\
\text { Menyebut Bhayangkara FC telah } \\
\text { menjuarai kompetisi yang tidak } \\
\text { berkualtias }\end{array}$ & $\begin{array}{l}--- \\
\text { (tidak tercantum } \\
\text { dalam teks) }\end{array}$ & $\begin{array}{l}\text { PSSI berkomitmen } \\
\text { untuk mewujudkan } \\
\text { sepakbola yang } \\
\text { berkualitas }\end{array}$ \\
\hline $\begin{array}{l}\text { Memberikan } \\
\text { solusi untuk } \\
\text { penyelesaian } \\
\text { masalah }\end{array}$ & $\begin{array}{l}\text { (tidak tercantum } \\
\text { dalam teks) }\end{array}$ & (tidak tercantum dalam teks) & $\begin{array}{l}\text { Bhayangkara } \\
\text { tinggal menjaga } \\
\text { ritme permainan } \\
\text { di laga terakhir }\end{array}$ & $\begin{array}{l}\text { Klub peserta } \\
\text { kompetisi } \\
\text { harus paham } \\
\text { tanggungjawabnya }\end{array}$ \\
\hline
\end{tabular}

(Sumber: hasil analisis)

masing organisasi dapat memberikan penjelasan sekaligus menonjolkan kepentingan mereka dalam sebuah kasus. Ini terlihat dari perbedaan bingkai pesan antara klub peserta kompetisi, operator kompetisi dan federasi sepakbola. Perbedaan kepentingan ini justru dapat mempertajam konflik, karena ada kecenderungan saling menyalahkan di antara pihak tersebut.

Penelitian ini memiliki keterbatasan karena hanya meneliti satu sampel pernyataan dari masing-masing pihak. Keterbatasan lain adalah karena tidak adanya data pernyataan resmi dari Bhayangkara FC di laman resmi klub tersebut. Menurut Manoli (2016), minimnya data akibat minimnya akses menuju sumber informasi menjadi penghambat dalam pengembangan penelitian mengenai manajemen krisis di industry olahraga

Untuk penelitian selanjutnya, penulis menyarankan melakukan penelitian dengan tujuan membandingkan frame pernyataan resmi organisasi dengan pemberitaan media dan/atau pandangan masyarakat berkaitan dengan kasus tertentu. Saran ini 
berdasarkan tinjauan teoritik yakni dalam membingkai pesan, organisasi berusaha untuk mempengaruhi frame media dan frame opini publik. Tentu agar media dan/ atau publik tertarik untuk menggunakan dan mempercayai pesan tersebut, maka isi pesan harus sesuai dengan kebutuhan media dan/atau publik (Kriyantono, 2014). Dengan membandingkan, maka kita dapat mengetahui apakah upaya frame yang dilakukan oleh organisasi berhasil atau tidak.

Penelitian juga dapat dilakukan dengan menganalisis penggunaan media sosial resmi masing-masing pihak dalam situasi krisis. Lewat media sosial, organsiasi dan publik bisa berinteraksi secara lansgung. Dengan media sosial dapat diketahui bagaimana repson publik terhadap pesan komunikasi yang disampaikan.

\section{DAFTAR PUSTAKA}

Bernstein, B. (2012) "Crisis Management and Sports in the Age of Social Media: A Case Study Analysis of the Tiger Woods Scandal" The Elon Journal of Undergraduate Resarch in Communications, 3 (2), Fall: 62-75. URL: https://www. elon.edu/docs/e-web/academics/ com munications/research/ vol3no2/05BernsteinEJFall12.pdf. Tanggal akses : 6 Mei 2018

Brown, N.A., Brown, K.A., \& Dickhaus, J. (2014) "When Crisis Strikes The Field". Andrew C.Billings \& Marie Hardin (Editors). Routledge Handbook of Sport and New Media. London: Routledge

Dewa Broto, G.S. (2014) The PR: Tantangan Public Relations di Era Keterbukaan Informasi. Jakarta : Gramedia Pustaka Utama
Isaacson, T. (2010) Sports Public Relations. URL : http://epublications. marquette.edu/cgi/viewcontent. cgi? article $=1080 \&$ context $=$ comm_fac , diakses 3 Januari 2018

Kitchin, P.J. \& Purcell, P.A (2017) "Examining Sport Communication Practitioners' Approachs to Issues Management and Crisis Response in Northern Ireland" Public Relations Review 43: 661670. URL: https://reader.elsevier.com/ reader/sd/06E0D602FCD2162EB4E 9F9B77EAC3FAA099FAB02A468B 21038D329D6B81AEAFF69BF680 544F1CD9E52EB44AD51B4436A. Tanggal akses: 10 Mei 2018

Kriyantono, R. (2012) Public Relation \& Crisis Management (Pendekatan Critical Public Relations, Etnografi Kritis \& Kualitatif). Jakarta : Kencana Prenada Media Group

Kriyantono, R. (2014) Teori Public Relations Perspektif Barat dan Lokal (Aplikasi Penelitian dan Praktik). Jakarta : Kencana Prenada Media Group

Manoli, E.A. (2016) Crisis communications management in football clubs. URL: https://dspace.lboro.ac.uk/dspacejspui/bitstream/2134/21886/3/ Crisis\%20 Communication $\% 20$ Management\%20in\%20Football\%20 Clubs_APA\%20Checked.pdf . Tanggal akses : 6 Mei 2018

Novitaria, I. (2017) "The Role of Public Relations In Sport Organization In Indonesia" Journal Advanced Science Letters, 23 (1), January: 528-531

Prastya, N.M (2011) "Komunikasi Krisis di Era New Media dan Social Media" Jurnal Komunikasi, 6 (1), Oktober : 1-20. URL: http://journal.uii.ac.id/jurnalkomunikasi/article/view/6374/5734. Tanggal akses : 1 Januari 2018 
Sabreyna, A. \& Moertijoso. R.B (2015). "Strategi Media Relations Humas PT Pelabuhan Indonesia III dalma Handling Crisis Pemberitaan Media". Jurnal Komunikasi, IX (1), Maret : 57-72. URL: http://journal.trunojoyo.ac.id/ komunikasi/article/view/1152/975 . Tanggal akses : 12 Mei 2018

Serbanica, D. \& Constantinescu, M. (2016) Using Public Relations in Sport. URL : http://www.academia.edu/26839916/ Using_public_relations_in_sports. Tanggal akses : 7 Mei 2018

Siahaan, P (2014) The Big Pang Theory (Editor : Farah Rizki). Jakarta : Elex Media Komputindo

Syadzwina, A.W. (2016) "Peran Public Relations dan Media Officer dalam Organisasi Sepakbola" dalam Sirajudin Hasbi dan Ferry Tri Adi (Editors). Sepakbola 2.0. Fandom: Yogyakarta
Utami, N.W. (2014) Komunikasi dalam Resolusi Konflik Beragama (Studi Pada Upaya Komunikasi Aktor-Aktor dalam Resolusi Konflik Ahmadiyah di Tasikmalaya). Master Tesis. Pascasarjana Ilmu Komunikasi, Fakultas Ilmu Sosial dan Ilmu Politik, Universitas Gadjah Mada Yogyakarta

Zoch, L.M. dan Molleda, J.C. (2006) "Buliding a Theoretical Model of Media Relations using Framing, Information Subsidies, and Agenda Buliding" dalam Carl H.Botan \& Vincent Hazelton (Editors). Public Relations Theory II. New Jersey: Lawrence Erlbam Associates 